\title{
Evaluasi Kemantapan Permukaan Jalan Berdasarkan International Roughness Index Pada 14 Ruas Jalan di Kota Yogyakarta
}

\author{
Ardilson Pembuain*, Sigit Priyanto, Latif Budi Suparma \\ Departemen Sipil dan Lingkungan, Fakultas Teknik, Universitas Gadjah Mada, \\ Jl. Grafika No. 2, Kampus UGM, Yogyakarta, Indonesia 55281
}

\begin{abstract}
Abstrak
Jalan yang memiliki kekasaran (roughness) permukaan yang buruk dapat menyebabkan ketidaknyamanan bagi pengguna jalan, kecelakaan lalu lintas, peningkatan beban dinamis pada permukaan jalan sehingga mempercepat proses kerusakan jalan, serta kerusakan kendaraan. Penelitian ini bertujuan untuk mengevaluasi kemantapan kondisi jalan berdasar nilai international roughness index (IRI). Evaluasi kondisi kemantapan jalan dilakukan pada 14 ruas jalan di Kota Yogyakarta, dengan perincian 4 ruas jalan arteri sekunder dan 10 ruas jalan kolektor sekunder. Data nilai kekasaran permukaan jalan (IRI) diperoleh dengan menggunakan alat NAASRA roughness meter yang mengacu pada SNI 03-3426-1994. Evaluasi kemantapan kondisi jalan dilakukan dengan membandingkan nilai IRI hasil survei dan batasan nilai IRI yang ditetapkan oleh Direktorat Jenderal Bina Marga. Hasil penelitian menunjukkan 14 ruas jalan yang dievauasi 64\% dalam kondisi sedang dan 36\% dalam kondisi baik. Dari ke-14 ruas jalan tersebut, ruas jalan Sisingamangaraja, Lowanu, dan Sugeng Jeroni memiliki nilai IRI tertinggi secara bururutan sehingga ketiga ruas jalan tersebut lebih diprioritaskan untuk mendapatkan penanganan.
\end{abstract}

Kata kunci: international roughness index; NAASRA meter; kemantapan permukaan jalan; ruas jalan arteri sekunder; ruas jalan kolektor sekunder; prioritas penanganan

\begin{abstract}
[Title: Evaluation of Road Surface Stability Based on the International Roughness Index on 14 Roads in Yogyakarta City ] Roads that have poor surface roughness can cause uncomfortable to road users, traffic accidents, increase dynamic loads on the road surface, thereby accelerating the process of road damage, and damage to vehicles. This research aims to evaluate the stability of road conditions based on the international roughness index (IRI). Evaluation of road stability conditions was carried out on 14 road segments in the city of Yogyakarta, with details of four secondary arterial road segments and 10 secondary collector road segments. Data on road surface roughness (IRI) values were obtained using NAASRA roughness meter which refers to SNI 03-3426-1994. Evaluation of the stability of road conditions is done by comparing the IRI values of the survey results and the limits of IRI values determined by the Directorate General of Highways. The results showed that 14 roads were evaluated, $64 \%$ were in moderate condition and $36 \%$ were in good condition. Of the 14 roads, the Sisingamangaraja, Lowanu, and Sugeng Jeroni roads have the highest IRI value in a sequence so that the three road segments are prioritized for handling.
\end{abstract}

Keywords: international roughness index; NAASRA meter; road surface stability; secondary arterial road segments; secondary collector road segments; handling priority

\section{Pendahuluan}

Tingkat kekasaran suatu infrastruktur jalan

${ }^{*}$ Ardilson Pembuain

E-mail: ardilson_pembuain@yahoo.com dinyatakan dengan international roughness index (IRI). IRI adalah skala kekasaran berdasarkan respon kendaraan terhadap kekasaran permukaan jalan (Gillespie, 1992). IRI dikembangkan oleh World Bank sekitar tahun 1980-an (Sayers dan Karamihas, 1998; Uhlmeyer dkk., 2016). Berdasarkan eksperimen World 


\section{TEKNIK, 39 (2), 2018, 127}

Bank, IRI dapat ditentukan dengan bantuan Maymester, NAASRA, Bump Integrator, BPR roughmeter, Rod and Level Survey, TRRL beam, APL trailer, dan GMR Profilometer (Peterson, 1987).

NAASRA roughness meter merupakan salah satu metode pengukuran nilai IRI yang biasa dilakukan di Indonesia dan metode pelaksanaannya mengacu pada SNI 03-3426-1994 (1994). Nilai IRI di Indonesia digunakan untuk mengetahui dan mengevaluasi kondisi kemantapan permukaan infrastruktur jalan. Direktorat Jenderal Bina Marga menetapkan nilai batas IRI yang dapat dipakai untuk mengevaluasi kekasaran infrastruktur jalan yang terbagi dalam empat kondisi kekasaran infrastruktur jalan yaitu baik, sedang, rusak ringan, dan rusak berat (Siahaan dan Surbakti 2011).

Pengukuran kekasaran permukaan jalan dibutuhkan karena ketidaksempurnaan geometri permukaan infrastruktur jalan akan menyebabkan getaran pada kendaraan pada saat melintasi jalan tersebut (Gillespie, 1992). Getaran pada kendaraan selanjutnya akan merambat ke tubuh pengendara atau penumpang sehingga akan mengurangi kualitas berkendara (Cantisani dan Loprencipe, 2010).

Jika kekasaran permukaan infrastruktur jalan tidak dipelihara dan dirawat secara berkala maka akan berdampak buruk pada pengguna jalan dan infrastruktur jalan itu sendiri. Dampak langsung kekasaran jalan yang buruk diantaranya, memberikan tekanan pada struktur kendaraan, menurunkan tingkat kenyamanan bagi pengguna jalan, meningkatkan beban dinamis pada permukaan jalan oleh roda kendaraan sehingga dapat mempercepat kerusakan pada struktur jalan, dan mengurangi keefektifan transmisi kendaraan, khususnya yang berhubungan dengan pengemudian dan tindakan pengereman karena hal ini sangat berhubungan dengan risiko kecelakaan dan peningkatan kelelahan pengguna jalan (Cantisani dan Loprencipe, 2010). Dampak tidak langsung kondisi kekasaran jalan yang buruk yaitu bertambahnya biaya operasional kendaraan diantaranya, biaya konsumsi bahan bakar minyak (BBM), biaya keausan ban, biaya perawatan dan perbaikan kendaraan, serta biaya depresiasi (Robbins dan Tran 2016; Tehrani, 2015; Ng, 2015). Dengan demikian, dapat dikatakan bahwa evaluasi dan perawatan kekasaran permukaan jalan yang teratur akan memberikan manfaat yang sangat besar bagi pengguna jalan.

Berdasarkan penjabaran di atas, penelitian ini bertujuan untuk mengevaluasi kondisi kemantapan pada 14 ruas jalan di Kota Yogyakarta dengan menggunakan nilai batas IRI yang ditentukan oleh Direktorat Jenderal Bina Marga. Evaluasi terhadap kondisi kemantapan infrastruktur jalan dengan menggunakan nilai IRI diharapkan dapat menjadi masukan bagi otoritas infrastruktur jalan sebagai tool mentainance dan perbaikan kondisi jalan yang memiliki kondisi buruk dan berbahaya bagi para pengguna jalan.

Penggunaan nilai IRI untuk mengevaluasi kondisi kemantapan infrastruktur jalan telah dilakukan oleh beberapa peneliti sebelumnya. Berdasarkan proses telaah pustaka yang dilakukan, setidaknya ada 6 penelitian dalam rentang waktu 2016 sampai 2018 yaitu Tho'atin dkk. (2016), Sanjaya dkk. (2017), Srianty dkk. (2017), Fatra dkk. (2017), Zulfan dkk. (2018), dan Muhsin. (2018). Perbedaan utama penelitian yang dilakukan saat ini dengan penelitian-penelitian di atas terletak pada jumlah indikator yang digunakan untuk evaluasi kondisi kemantapan infrastruktur jalan. Tho'atin dkk. (2016) menggunakan indikator IRI, SDI, dan PCI, Sanjaya dkk. (2017) menggunakan indikator IRI dan SDI, Srianty dkk. (2017) menggunakan indikator IRI, SDI, dan LHR, Fatra dkk. (2017) menggunakan indikator IRI dan LHR, Zulfan dkk. (2018) menggunakan indikator IRI, SDI, dan data kondisi jalan, dan Muhsin (2018) menggunakan indikator IRI, SDI, IRI, dan tingkat konektivitas.

Penelitian ini berfokus pada evaluasi kemantapan jalan berdasarkan nilai IRI dan penggunaan nilai IRI sebagai indikator dalam prioritas penentuan penanganan kerusakan infrastruktur jalan. Penelitian ini diharapkan dapat memberikan masukan bagi otoritas infrastruktur jalan di Kota Yogyakarta terkait kondisi kemantapan dan proses penanganan pada jalan yang ditinjau.

\section{Metode Penelitian}

\section{Lokasi Penelitian}

Penelitian ini dilakukan di kota Yogyakarta, Indonesia. Jenis jalan yang digunakan dalam penelitian ini adalah jalan arteri sekunder dengan kecepatan rencana 50 sampai $80 \mathrm{~km} / \mathrm{jam}$ dan jalan kolektor sekunder dengan kecepatan rencana 30 sampai 50 km/jam (Standar Geometri Jalan Perkotaan, 2004). Identifikasi ruas jalan arteri sekunder dan kolektor sekunder di Kota Yogyakarta menggunakan Keputusan Walikota Yogyakarta Nomor 71 Tahun 2018 Tentang Penetapan Ruas-Ruas Jalan Kota Yogyakarta (2018) dan Keputusan Walikota Ruas-Ruas Jalan Menurut Kelasnya di Kota Yogyakarta (2013).

Penelitian ini mengevaluasi empat ruas jalan arteri sekunder dan 10 ruas jalan kolektor sekunder di kota Yogyakarta. Tabel 1 menunjukkan detail dari 14 ruas jalan yang dievaluasi. Gambar 1 menunjukkan peta dari 14 ruas jalan yang dievaluasi. Ruas jalan arteri sekunder berwarna hijau, sedangkan ruas jalan kolektor sekunder berwarna kuning. Seluruh ruas jalan yang dievaluasi dalam penelitian ini bertipe empat lajur dua arah tak terbagi (4/2 UD). Karakteristik jalan dua arah tersebut menyebabkan evaluasi kemantapan kekasaran dilakukan pada masing-masing arah jalan. 


\section{TEKNIK, 39 (2), 2018, 128}

\section{Data Penelitian}

Tingkat kenyamanan kendaraan yang dinilai dalam penelitian ini didasarkan atas nilai kekasaran permukaan jalan yang diwakili dengan nilai IRI. Nilai IRI dalam penelitian ini diperoleh dengan menggunakan alat NAASRA roughness meter sesuai SNI 03-3426-1994 (1994) Tentang Survei Kerataan Permukaan Perkerasan Jalan dengan Alat Ukur Kerataan NASSRA (Siahaan dan Surbakti, 2011). Pengambilan data kekasaran jalan dilakukan pada tanggal 3 sampai 6 September 2018. Visual alat NAASRA roughness meter terlihat pada Gambar 2.

Tabel 1. Data Jalan

\begin{tabular}{clcc}
\hline No & Nama Ruas Jalan & $\begin{array}{c}\text { Status } \\
\text { Jalan }\end{array}$ & $\begin{array}{c}\text { Kelas } \\
\text { Jalan }\end{array}$ \\
\hline 1 & Sugeng Jeroni & & \\
2 & MT Haryono & Arteri & II \\
3 & Mayjend Sutoyo & Sekunder & \\
4 & Gedong Kuning & & \\
5 & KH Wahid Hasyim & & \\
6 & Ipda Tut Harsono & & \\
7 & Brigjen Katamso & & \\
8 & Taman Siswa & & \\
9 & Veteran & Kolektor & II \\
10 & Gambiran & Sekunder & \\
11 & DI Panjaitan & & \\
12 & Sisingamangaradja & & \\
13 & Lowanu & & \\
14 & Imogiri Barat & \\
\hline mber:Keputusan Walikota Yogyakarta No. 214/KEP/2013
\end{tabular}

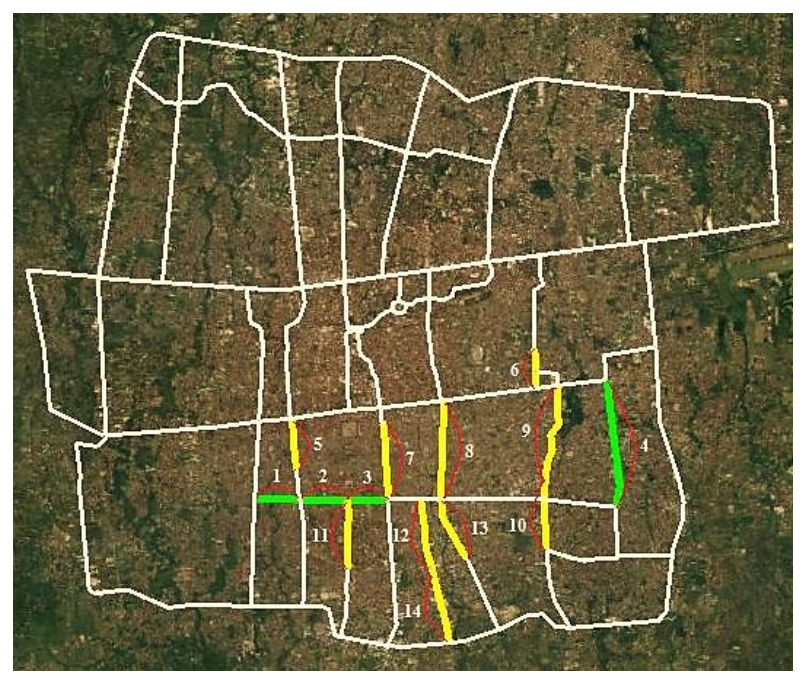

sumber:Maps 2018

Gambar 1. Peta ruas jalan di Kota Yogyakarta
3. Tingkat Kemantapan Berdasarkan Nilai IRI

Data IRI yang telah diperoleh kemudian dievaluasi dengan menggunakan standar yang dikeluarkan oleh Direktorat Jenderal Bina Marga seperti yang terlihat pada Tabel 2.

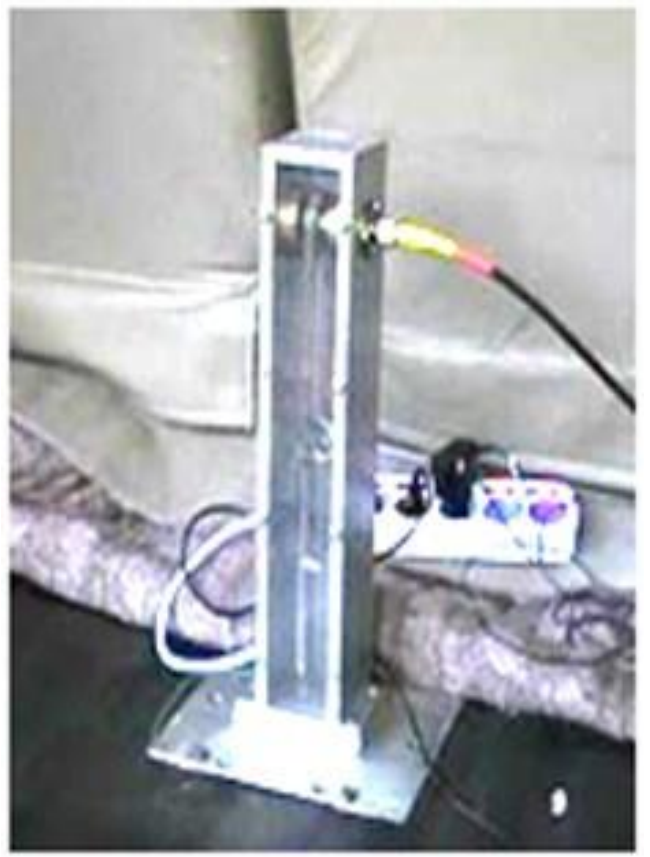

Gambar 2. NAASRA roughness meter sumber:BPPJN V Palembang

Tabel 2. Parameter international roughness index (IRI)

\begin{tabular}{lcc}
\hline $\begin{array}{c}\text { Kondisi } \\
\text { Jalan }\end{array}$ & IRI $(\mathbf{m} / \mathbf{k m})$ & $\begin{array}{c}\text { Tingkat } \\
\text { Kemantapan }\end{array}$ \\
\hline Baik & IRI rata-rata $\leq 4,0$ & Jalan mantap \\
Sedang & $4,1 \leq$ IRI rata-rata $\leq 8,0$ & \\
$\begin{array}{l}\text { Rusak } \\
\text { Ringan }\end{array}$ & $8,1 \leq$ IRI rata-rata $\leq 12$ & \\
$\begin{array}{l}\text { Rusak } \\
\text { Berat }\end{array}$ & IRI rata-rata $\geq 12$ & $\begin{array}{c}\text { Jalan tidak } \\
\text { mantap }\end{array}$ \\
\hline
\end{tabular}

sumber: Fatra dkk., 2017

Evaluasi tingkat kemantapan kondisi jalan dilakukan dengan membandingkan nilai standar IRI dari Direktorat Jenderal Bina Marga dan nilai IRI yang diperolah dari hasil survei. Sebaliknya, semakin kecil nilai IRI maka semakin besar nilai IRI maka semakin buruk atau semakin tidak mantap jalan tersebut. semakin baik atau semakin mantap jalan tersebut. Pembahasan dan saran akan diberikan berdasarkan hasil evaluasi tingkat kenyamanan berkendara. 


\section{TEKNIK, 39 (2), 2018, 129}

\section{Hasil Dan Pembahasan}

Hasil evaluasi kondisi kekasaran permukaan jalan arah normal dan opposite pada 4 ruas jalan arteri sekunder dan 10 ruas jalan kolektor sekunder di kota Yogyakarta ditunjukkan pada Tabel 3. Secara keseluruhan ke-14 ruas jalan tersebut memiliki kondisi baik dan kondisi sedang. Direktorat Jenderal Bina Marga menyarankan penanganan yang dapat dilakukan untuk kondisi jalan baik adalah pemeliharaan rutin, sedangkan untuk kondisi jalan sedang adalah pemeliharaan berkala. Jika tindakan perbaikan terlambat dilakukan maka dapat menyebabkan rusaknya kondisi struktur jalan sehingga biaya perbaikan infrastruktur jalan akan sangat besar. Selain itu, kondisi kerusakan tersebut akan memperbesar biaya operasional bagi pengguna jalan (Uhlemeyer, dkk., 2016). Penanganan yang tepat dan sesuai akan memperpanjang umur pelayanan infrastruktur jalan serta menambah keekonomisan pengguna jalan.

Penanganan kerusakan jalan sering terkendala dana yang tersedia. Jaringan jalan yang luas akan membutuhkan dukungan dana yang sangat besar dalam proses penanganan kerusakan jalan. Jika dana yang tersedia tidak cukup untuk penanganan jalan secara keseluruhan, prioritas penanganan menjadi pilihan yang paling logis agar dana yang dialokasikan lebih tepat sasaran, efektif dan efisien. Ruas jalan dengan nilai IRI yang tinggi sebaiknya diprioritaskan perbaikannya sehingga kualitas pelayanan infrastruktur jalan dapat tetap terjaga dengan baik

Nilai IRI pada Tabel 3 dapat digunakan untuk menentukan prioritas penanganan infrastruktur jalan yaitu dengan cara menggabungkan nilai IRI arah normal dan opposite setiap ruas jalan. Gambar 3 menampilkan penggabungan nilai IRI arah normal dan opposite dari masing-masing ruas jalan yang ditinjau, sedangkan Gambar 4 menampilkan besar persentase dari ke-14 ruas jalan yang diteliti yaitu $64 \%$ kondisi sedang dan $36 \%$ kondisi baik, dengan perincian empat ruas jalan arteri sekunder $50 \%$ kondisi sedang dan 50\% kondisi baik, sedang 10 ruas jalan kolektor sekunder $65 \%$ kondisi sedang dan $35 \%$ kondisi baik. Nilai IRI gabungan pada Gambar 3 menunjukkan bahwa dari ke-14 ruas jalan yang ditinjau, ruas jalan Sisingamangaraja, Lowanu dan Sugeng Jeroni adalah tiga ruas jalan yang memiliki nilai IRI tertinggi secara bururutan sehingga ketiga ruas jalan tersebut lebih diprioritaskan untuk dilakukan penanganan. Ketiga ruas jalan tersebut harus diprioritaskan dalam proses pemeliharaan berkala dibandingkan ruas jalan lainnya. Selain itu, tiga ruas jalan dengan nilai IRI yang paling kecil secara berturutturut adalah jalan Gambiran, Mayjend Sutoyo, dan MT Haryono. Prioritas penanganan yang tepat dan ditindaklanjuti dengan baik akan memberikan manfaat bagi pengguna infrastruktur jalan.

Tabel 3. Status Kemantapan Jalan berdasarkan nilai IRI

\begin{tabular}{|c|c|c|c|c|c|}
\hline Kode Ruas & Nama Jalan & Fungsi Jalan & Arah & Nilai IRI & Status \\
\hline \multirow{2}{*}{1} & \multirow{2}{*}{ Sugeng Jeroni } & \multirow{2}{*}{ Arteri Sekunder } & $\mathrm{N}$ & 4,80 & Sedang \\
\hline & & & Op & 4,52 & Sedang \\
\hline \multirow{2}{*}{2} & \multirow[b]{2}{*}{ MT Haryono } & \multirow{2}{*}{ Arteri Sekunder } & $\mathrm{N}$ & 3,74 & Baik \\
\hline & & & Op & 3,77 & Baik \\
\hline \multirow{2}{*}{3} & \multirow{2}{*}{ Mayjend Sutoyo } & \multirow{2}{*}{ Arteri Sekunder } & $\mathrm{N}$ & 3,76 & Baik \\
\hline & & & Op & 3,74 & Baik \\
\hline \multirow{2}{*}{4} & \multirow{2}{*}{ Gadong Kuning } & \multirow{2}{*}{ Arteri Sekunder } & $\mathrm{N}$ & 4,22 & Sedang \\
\hline & & & Op & 4,32 & Sedang \\
\hline \multirow{2}{*}{5} & \multirow{2}{*}{ KH Wahid Hasyim } & \multirow{2}{*}{ Kolektor Sekunder } & $\mathrm{N}$ & 3,99 & Baik \\
\hline & & & Op & 5,01 & Sedang \\
\hline \multirow{2}{*}{6} & \multirow{2}{*}{ Ipda Tut Harsono } & \multirow{2}{*}{ Kolektor Sekunder } & $\mathrm{N}$ & 4,72 & Sedang \\
\hline & & & Op & 4,04 & Sedang \\
\hline \multirow{2}{*}{7} & \multirow{2}{*}{ Brigjen Katamso } & \multirow{2}{*}{ Kolektor Sekunder } & $\mathrm{N}$ & 3,81 & Baik \\
\hline & & & Op & 3,92 & Baik \\
\hline \multirow{2}{*}{8} & \multirow{2}{*}{ Taman Siswa } & \multirow{2}{*}{ Kolektor Sekunder } & $\mathrm{N}$ & 4,15 & Sedang \\
\hline & & & Op & 4,09 & Sedang \\
\hline \multirow{2}{*}{9} & \multirow{2}{*}{ Veteran } & \multirow{2}{*}{ Kolektor Sekunder } & $\mathrm{N}$ & 3,94 & Baik \\
\hline & & & Op & 4,12 & Sedang \\
\hline \multirow[b]{2}{*}{10} & \multirow[b]{2}{*}{ Gambiran } & \multirow[b]{2}{*}{ Kolektor Sekunder } & $\mathrm{N}$ & 3,43 & Baik \\
\hline & & & Op & 3,91 & Baik \\
\hline \multirow[b]{2}{*}{11} & \multirow{2}{*}{ DI Panjaitan } & & $\mathrm{N}$ & 4,56 & Sedang \\
\hline & & Kolektor Sekunder & Op & 4,39 & Sedang \\
\hline 12 & Sicinoamanoaradia & Kolektor Selounder & $\mathrm{N}$ & 5,05 & Sedang \\
\hline 12 & SIsingantiangarauja & 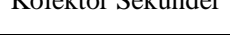 & Op & 4,75 & Sedang \\
\hline 13 & J очиари & Kolektor Serunder & $\mathrm{N}$ & 4,89 & Sedang \\
\hline 15 & Lowanu & 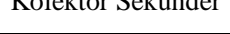 & Op & 4,81 & Sedang \\
\hline 14 & Imooiri Barat & Kolektor Sekunder & $\mathrm{N}$ & 3,73 & Baik \\
\hline 14 & ImIogint Daral & KOIEktor Seкunder & Op & 4,20 & Sedang \\
\hline
\end{tabular}




\section{TEKNIK, 39 (2), 2018, 130}

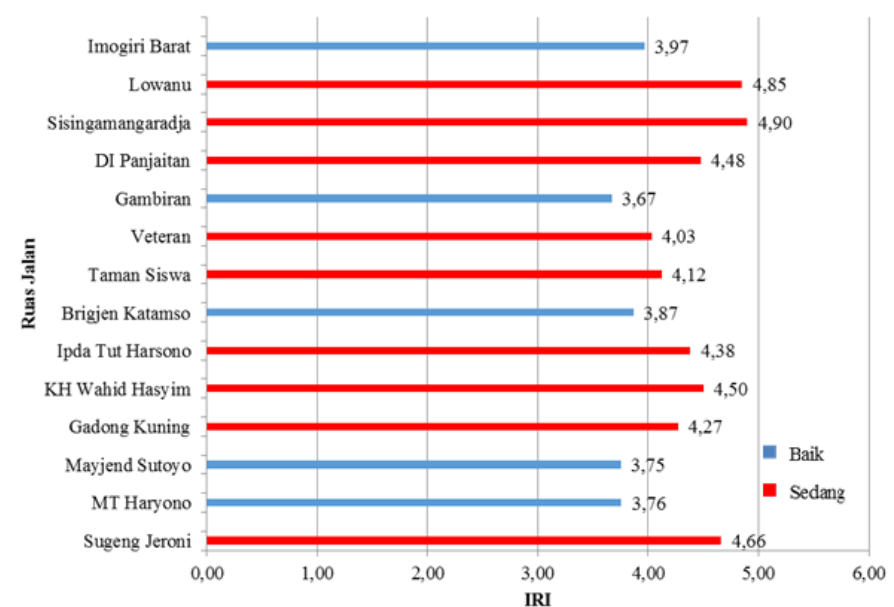

Gambar 3. Status kemantapan ruas jalan Sumber: hasil analisis

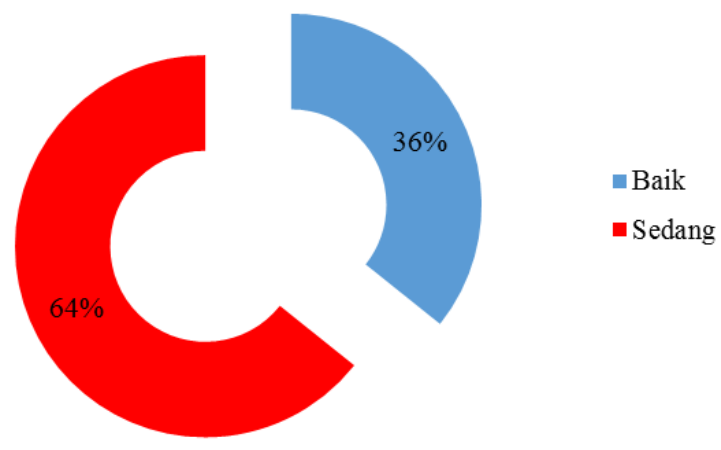

Gambar 4. Presentase kondisi ruas jalan. sumber: hasil analisis

\section{Kesimpulan}

Evaluasi kondisi kemantapan jalan berdasarkan nilai international roughness index (IRI) telah dilakukan pada 14 ruas jalan di Kota Yogyakarta. Hasil penelitian menunjukkan 14 ruas jalan yang dievauasi $64 \%$ dalam kondisi sedang dan 36\% dalam kondisi baik. Dari ke-14 ruas jalan tersebut, ruas jalan Sisingamangaraja, Lowanu, dan Sugeng Jeroni memiliki nilai IRI tertinggi secara bururutan sehingga ketiga ruas jalan tersebut lebih diprioritaskan untuk mendapatkan penanganan.

\section{Ucapan Terima Kasih}

Ucapan terima kasih disampaikan kepada PT. Parvid yang telah bekerjasama dalam proses pengambilan data IRI dengan menggunakan alat NAASRA roughness meter.

\section{Daftar Pustaka}

Cantisani, G. dan Loprencipe, G. (2010). Road
Roughness and Whole Body Vibration: Evaluation Tools and Comfort Limits. J. Transp. Eng., vol. 136, no. 9, pp. 818-826.

Gillespie, T. D. (1992). Everything You Always Wanted To Know About The IRI, But Were Afraid to Ask. Road Profile Users Gr. Meet.

Fatra, R., Purnawan, dan Putri, E. E. (2017). Analisa Kondisi Kemantapan Jalan Nasional Provinsi Riau Terhadap Volume Lalu Lintas Dan Alokasi Anggaran. J. Rab Construction Research, vol. 2, no. 1

Muhsin, T., Aryani S., R. A., dan Wiguna, I. P. A. (2018). Evaluasi Penerapan Standar Pelayanan Minimal Pada Ruas Jalan Provinsi Di Kota Kendari Sulawesi Tenggara. ITS Journal of Civil Engineering, Vol. 33, no. 1.

Ng, V. L. (2015). A Study Of Deterioration In Ride Quality On Ohio's Highways By Vincent.

Pemerintah Kota Yogyakarta. (2013). Keputusan Walikota Kota Yogyakarta Tentang Penetapan Ruas-ruas Jalan Menurut Kelasnya Di Kota Yogyakarta, pp. 1-19.

Pemerintah Kota Yogyakarta. (2018). Keputusan Walikota Kota Yogyakarta Tentang Penetapan Ruas-ruas Jalan Kota Yogyakarta, pp. 1-12.

Peterson, W.D.O. (1987). Road Deterioration And Maintenance Effects: Models For Planning And Management.

Pusat Studi Transportasi Badan Penelitian Dan Pengembangan Pekerjaan Umum. (1994). Tata Cara Survai Kerataan Permukaan Perkerasan Jalan Dengan Alat Ukur Kerataan Naasra. pp. 18.

Robbins, M. M. dan Tran, N. H. (2016). A Synthesis Report: Value Of Pavement Smoothness And Ride Quality To Roadway Users And The Impact Of Pavement Roughness On Vehicle Operating Costs.

Sanjaya, Y. A., Rosalina dan Syarwan. (2017). Evaluasi Tingkat Kerusakan Permukaan Jalan Untuk Menentukan Jenis Penanganan Dengan Sistem Penilaian Menurut Bina Marga (Studi Kasus Jalan Nasional Bireuen-Bts. Kota Lhokseumawe, Kecamatan Krueng Geukueh Mulai Sta 253+ 000 S/D Sta 257+ 000). J. Sipil Sains Terapan, vol. 10, issue 1, no. 1.

Sayers, M. W. dan Karamihas, S. M. (1998). The Little Book Of Profiling. Univ. Michigan.

Siahaan, D. A. dan Surbakti, M. S. (2011). Analisis Perbandingan Nilai IRI Berdasarkan Variasi Rentang Pembacaan NAASRA. J. Tek. Sipil $U S U$, vol. 3, no. 3 .

Srianty, J., Isya, M., dan Anggraini, R. (2017). Analisis Kondisi Kemantapan Jalan Dengan Lalu Lintas 


\section{TEKNIK, 39 (2), 2018, 131}

Harian Rata-Rata Pada Jalan Arteri Sekunder. J. Teknik Sipil Universitas Syiah Kuala, vol. 1, special issue no. 1.

Standar Geometri Jalan Perkotaan. (2004). Indonesia.

Tehrani, S. S. (2014). Performance Measurement Using IRI And Collision Rates In The Province Of Alberta.

Tho'atin, U., Setyawan, A., dan Suprapto, M. (2016). Penggunaan Metode International Roughness Index (Iri), Surface Distress Index (Sdi) Dan
Pavement Condition Index (Pci) Untuk Penilaian Kondisi Jalan Di Kabupaten Wonogiri. Prosiding Semnastek.

Uhlmeyer, J. D., Luhr, dan Rydholm, T. (2016). Pavement Asset Management.

Zulfan, E., Saleh, S. M., dan Yunus, Y. (2018). Penilaian Kondisi Jalan Pada Ruas Jalan KM. 77 (Batas Pidie) - Batas Kota Sigli. J. Teknik Sipil Universitas Syiah Kuala, vol. 1, special issue no. 3. 